\title{
Preparation and characterisation of uranium and plutonium quality control samples for isotope dilution mass spectrometry measurements and uncertainty estimation
}

\author{
Célia Venchiarutti ${ }^{1} \mathbb{D} \cdot$ Rožle Jakopič $^{1} \cdot$ Carmel Hennessy $^{1} \cdot$ Kalman Toth $^{1}$
}

Received: 16 November 2020 / Accepted: 31 December 2020 / Published online: 25 January 2021

(c) The Author(s) 2021

\begin{abstract}
This paper presents the preparation, characterisation and validation of two quality control (QC) samples for the measurement of plutonium and uranium contents by isotope dilution mass spectrometry (IDMS). These two QC samples were then used at the JRC-Geel G.2's laboratory to monitor the performance of IDMS measurement results in line with the ISO 17025 and ISO 17034. The QC samples were prepared from two certified reference materials, namely the NBL-126 (Pu) and CRM 116-A (U). The values for the ${ }^{235} \mathrm{U}$ and ${ }^{239} \mathrm{Pu}$ amount contents of the $\mathrm{QC}$ samples were assigned based on the gravimetric preparation of the solutions and verified by independent IDMS measurements. Their use as part of a broader in-house spike inter-calibration campaign, notably during participations in proficiency tests, is also highlighted. Finally, using these two IDMS QC samples, a detailed approach to the IDMS uncertainty evaluation, according to the Guide to the expression of uncertainty in measurement (GUM, 2008) is presented on various examples.
\end{abstract}

Keywords Quality control $\cdot$ Certified reference materials $\cdot$ Mass spectrometry $\cdot$ Plutonium $\cdot$ Uranium $\cdot$ Nuclear safeguards

\section{Introduction}

The JRC-Geel G.2 has a long-standing experience in production and certification of isotopic nuclear reference materials and providing reference measurements in support to Nuclear Safeguards and Nuclear Security. They are produced applying state-of-the art analytical procedures and in compliance with international guidelines [1-3].

The ISO/IEC 17,025 [1] requires laboratories to evaluate the measurement uncertainty of their results $[4,5]$. For many years, the uncertainty evaluation has been an important aspect in the certification process at JRC-Geel G.2 to provide fit-for-purpose and reliable certified reference materials (CRMs) to users. The fundamental role of CRMs is to establish traceability of a measurement result to a primary unit, as defined in the SI system. Furthermore, measurement results with appropriately estimated uncertainties

Célia Venchiarutti

celia.venchiarutti@ec.europa.eu

1 Directorate G-Nuclear Safety and Security, G.2-Standards for Nuclear Safety, Security and Safeguards Unit, European Commission, Joint Research Centre (JRC), Retieseweg 111, 2440 Geel, Belgium allow meaningful comparison of the results (comparability) amongst each other or against a reference value.

The concept of "uncertainty" as a quantifiable attribute is relatively new and was introduced by GUM in 1993 (Guide to Expression of Uncertainty in Measurement) [6]. However, error and the error analysis have long been part of the practice of a measurement science. Uncertainty is a parameter associated with the result of a measurement that characterises the dispersion of the values that could reasonably be attributed to the measurand (VIM) [7]. It is a measure of the "quality" of a measurement result.

The GUM [6], often referred to as a bottom-up approach, represents a standardised way of expressing uncertainty in measurements. The measurement method is described by a model equation where all input quantities comprising the final measurement result are stated. To each input quantity, an uncertainty is assigned either through experimentation (e.g. measurement, Type A) or via other sources (e.g. expert knowledge, published data, material certificates, Type B), and combined by using the law of propagation of uncertainties to obtain one combined standard uncertainty [6].

The GUM Workbench ${ }^{\odot}$ [8] is a software developed by Metrodata $\mathrm{GmbH}$ (Germany) and in use for many years at the JRC-Geel G.2 for the calculation of measurement 
results and their uncertainty estimation. It offers the possibility to determine an uncertainty budget [7], which provides a valuable feedback to the analyst. It identifies the dominant components of the combined standard uncertainty for the measurand and allows for better understanding, management and improvement of the measurement process. Furthermore, it enhances the transparency in the uncertainty calculation [9].

In order to ensure the provision of reliable reference materials and reference measurements, stringent quality assurance (QA) and quality control (QC) regimes need to be implemented by laboratories. These include regular participation of a laboratory in external quality assessments such as proficiency testing (PT) and inter-laboratory comparison (ILC) to monitor and demonstrate its performance. In addition, laboratories need to have internal QA/QC procedures in place to ensure continuous monitoring of the performance of analytical procedures. One way to apply this is through analysis of quality control (QC) samples [10-12].

The (certified) reference materials provided by the JRCGeel G.2 are applied mainly in mass spectrometry for instrument calibration, method validation and quality control. Isotope Dilution Mass Spectrometry (IDMS) is commonly applied for accurate measurements of uranium and plutonium content in many applications [13-16].

In this paper, we describe the preparation and characterisation of two QC samples for the measurement of uranium and plutonium contents by IDMS. Two high purity certified metals were selected as source materials for the gravimetric preparations. Furthermore, the evaluation of uncertainties for the IDMS measurements according to the GUM will be discussed. A few examples of the assignment of the uncertainties associated with QC samples, other CRM materials and QC charts, will be presented.

\section{Experimental}

\section{Source materials and spike CRMs}

$\mathrm{U}$ and $\mathrm{Pu}$ certified reference metals from the New Brunswick Laboratory Program Office (NBL PO, USA) [17] were selected for the preparation of the $\mathrm{U}$ and $\mathrm{Pu} \mathrm{QC}$ solutions:

- CRM 126/NBL $126\left({ }^{239} \mathrm{Pu}\right)$, a metal piece of ca. $1 \mathrm{~g}$, certified for Pu purity (99.962(18) $\mathrm{g} \mathrm{kg}^{-1}$ ) and ${ }^{239} \mathrm{Pu}$ abundance $\left(n\left({ }^{239} \mathrm{Pu}\right) / n(\mathrm{Pu})=97.925(18)\right.$ At \% $)$ as of October 1,1985 [18]

- CRM 116-A $\left({ }^{235} \mathrm{U}\right)$, a metal piece of ca. $1 \mathrm{~g}$, certified for $\mathrm{U}$ amount content $\left(0.99945(14) \mathrm{g} \mathrm{U} \mathrm{g}^{-1}\right.$ metal), isotope amount ratios and abundances (e.g. $\left.n\left({ }^{235} \mathrm{U}\right) / n(\mathrm{U})\right)$ as of October 31, $2013[19,20]$
The following spike materials and proficiency test samples were used in IDMS analyses:

- KRI-RM2-662-2004 (hereafter referred to as Pu KRIRM2) ${ }^{242} \mathrm{Pu}$ spike with a mass fraction of $94.20(08)$ $\mu \mathrm{g}{ }^{242} \mathrm{Pu} \mathrm{g}^{-1}$ solution (May 24, 2004) and KRIRM1-650-2008 (hereafter referred to as U KRI-RM1) ${ }^{233} \mathrm{U}$ spike with a mass fraction of $0.9885(07) \mathrm{mg}$ ${ }^{233} \mathrm{U} \mathrm{g}^{-1}$ solution (July 01, 2008) from V.G. Khlopin Radium Institute, Russia.

- EQRAIN 15U and EQRAIN 16U certified test samples with ${ }^{238} \mathrm{U}$ mass fraction from CEA/CETAMA, France. The CEA/CETAMA (French Commissariat à l'Energie Atomique et aux Energies Alternatives, de la Direction de l'Energie Nucléaire) organises regularly proficiency testing, known as EQRAIN (Assessment of the Quality of Analysis Results in the Nuclear Industry) for the analysis of $\mathrm{U}$ or $\mathrm{Pu}$ amount contents in nitrate solutions [21].

- IRMM-046c mixed ${ }^{233} \mathrm{U} /{ }^{242} \mathrm{Pu}$ spike mixed ${ }^{233} \mathrm{U} /{ }^{242} \mathrm{Pu}$ spike with certified amount contents of ${ }^{233} \mathrm{U}$ and ${ }^{242} \mathrm{Pu}$ of 4.4627(10) $\mu \mathrm{mol} \mathrm{g}^{-1}$ solution and 0.35491(15) $\mu \mathrm{mol} \mathrm{g}^{-1}$ solution, respectively, from JRC Geel, Belgium.

All the uncertainties given in parenthesis for each CRM described above, applied to the two last digits and correspond to the expended uncertainties with a coverage factor $k=2$.

\section{Metrological weighing}

Weighing was performed by the substitution method [22, 23]. The mass is determined through comparison with mass standards (calibrated certified weights) by bracketing the weighing of the "unknown sample (U)" with the mass standards (S) of a similar mass as the one of the unknown sample. The so-called SUUS weighing scheme (also known as $\mathrm{ABBA}$ ) was used and the sequence was repeated twice in order to achieve the uncertainty requirements. The balance was therefore used as a comparator and consequently any linearity effects and drift during the weighing sequence were cancelled out. Temperature, air pressure and relative humidity were recorded during weighing to correct for the air buoyancy.

\section{Preparation of $\mathrm{U}$ and $\mathrm{Pu} \mathrm{QC}$ solutions}

To remove surface oxidation products prior to weighing, the NBL 126 and CRM 116-A metals were cleaned by chemical etching (CRM 116-A) and by electro-polishing (NBL 126) according to instructions on the respective metal certificates $[17,24]$. 
The uranium metal was transferred to a $500 \mathrm{~mL}$ glass flask containing about $200 \mathrm{~mL}$ of Suprapur® $8 \mathrm{M} \mathrm{HNO}_{3}$. The solution was heated on a hot plate at ca. $120^{\circ} \mathrm{C}$ for $2 \mathrm{~h}$ to dissolve the uranium metal. After the metal had dissolved, additional $8 \mathrm{M} \mathrm{HNO}_{3}$ was added to obtain about $350 \mathrm{~mL}$ of solution with a mass fraction of approximately $3 \mathrm{mg} \mathrm{U} \mathrm{g}^{-1}$. The plutonium metal was dissolved in a $1 \mathrm{~L}$ glass flask by adding $20 \mathrm{~mL}$ Suprapur® $6 \mathrm{M} \mathrm{HCl}$. The Pu metal dissolution was rapid (within $10 \mathrm{~min}$ ) without any heating required. About $500 \mathrm{~mL} 8 \mathrm{M} \mathrm{HNO}_{3}$ was added to obtain a solution with a mass fraction of approximately $1.5-2 \mathrm{mg} \mathrm{Pu} \mathrm{g}^{-1}$. These concentrations were selected as suitable for spiking of the wide range of safeguards samples analysed in our laboratory. Both solutions were homogenised for a few days by periodic swirling by hand.

As solutions stored in flasks will evaporate over time, aliquots were dispensed into quartz ampoules with a PTFE screw-cap (tight for high vacuum until $10^{-6} \mathrm{mbar}$ ). A total of 36 units of each QC sample were prepared, each containing about $4 \mathrm{~mL}$ of solution in $8 \mathrm{M} \mathrm{HNO}_{3}$. The remaining solutions in the flasks were stored under weight control.

\section{Spiking and chemical treatment}

Blends using various spikes were prepared by metrological weighing as described above [23]. Masses of the spikes and samples in the blends were in the range of $0.5-3 \mathrm{~g}$ to optimise the IDMS measurements (e.g. to obtain spike-to-blend ratios between 1 and 10) taking into account the availability of the spike material and the number of required replicates [25].

Isotopic equilibration (homogenisation) of the spike and sample was achieved prior to separation by performing a redox (reduction-oxidation) step in which the oxidation state of plutonium and uranium was adjusted to $\mathrm{Pu}$ (IV) and $\mathrm{U}$ (VI), respectively [26]. Blend solutions were evaporated to near dryness and re-dissolved in $200 \mu \mathrm{L}$ of $2 \mathrm{M} \mathrm{HNO}_{3}$. Then, $50 \mu \mathrm{L}$ of $1.25 \mathrm{M} \mathrm{FeCl}_{2}$ and $100 \mu \mathrm{L}$ of $1 \mathrm{M} \mathrm{NH}_{2} \mathrm{OH} \cdot \mathrm{HCl}$ were added to reduce all plutonium in solution to $\mathrm{Pu}$ (III) while the uranium was kept in $\mathrm{U}(\mathrm{VI}) .100 \mu \mathrm{L}$ of $1 \mathrm{M} \mathrm{NaNO}_{2}$ was then added to oxidise the $\mathrm{Pu}$ (III) to $\mathrm{Pu}$ (IV). Finally, ca. $450 \mu \mathrm{L}$ of concentrated $\mathrm{HNO}_{3}$ was added to obtain a solution (of less than $1 \mathrm{~mL}$ ) in $8 \mathrm{M} \mathrm{HNO}_{3}$.

The separation (purification) was carried out by passing the sample solution through pre-conditioned anion-exchange columns (Bio-rad AG® $1 \times 4,100-200$ mesh, $\mathrm{Cl}^{-}$form). The sample was added then the column was first washed with a few $\mathrm{mL} 8 \mathrm{M} \mathrm{HNO}_{3}$ to remove the majority of the metal ions (e.g. iron from redox) before the uranium was eluted with $10 \mathrm{~mL} 8 \mathrm{M} \mathrm{HNO}_{3}$. The plutonium was eluted from the column with $10 \mathrm{~mL} 0.35 \mathrm{M} \mathrm{HNO}_{3}$. This purification procedure was repeated for samples spiked with a mixed ${ }^{233} \mathrm{U} /{ }^{242} \mathrm{Pu}$ spike (e.g. IRMM-046c) to remove the residual uranium in the plutonium fraction that could interfere in the mass-spectrometric measurements (e.g. the ${ }^{238} \mathrm{U}$ on the ${ }^{238} \mathrm{Pu}$ signal) [27].

\section{IDMS measurements}

The purified fractions were evaporated and re-dissolved in $1 \mathrm{M} \mathrm{HNO}_{3}$ to obtain $\mathrm{Pu}$ and $\mathrm{U}$ solutions of approximately $50 \mathrm{ng} \mu \mathrm{L}^{-1}$ and $100 \mathrm{ng} \mu \mathrm{L}^{-1}$, respectively. $1 \mu \mathrm{L}$ of these solutions was dried onto degassed zone-refined rhenium filaments (double filament configuration) for mass spectrometric measurements. Isotope ratio measurements were performed on a Triton Thermo Fischer Scientific (TIMS, Bremen, Germany) using the total evaporation (TE) method [28-31].

In the TE method, the evaporation (sample) filament is heated up to maintain a steady intensity and measured until the entire sample is consumed. The signals of each isotope are integrated over the entire measurement period. In this way, the mass fractionation effects are minimised. A small fractionation effect can still be observed depending on the sample loading, sample amount and heating procedure. This was corrected by measuring together with the samples, isotopic reference materials, IRMM-290b/A3 and IRMM074/10 for Pu and $\mathrm{U}$, respectively.

The $\mathrm{U}$ and $\mathrm{Pu}$ contents in blends were determined using the following general IDMS equation [15]:

$c_{\mathrm{x}}=c_{\mathrm{y}} \cdot \frac{m_{y}}{m_{x}} \cdot \frac{R_{\mathrm{y}}-R_{\mathrm{b}}}{R_{\mathrm{b}}-R_{\mathrm{x}}} \cdot \frac{\Sigma\left(R_{i}\right)_{x}}{\Sigma\left(R_{i}\right)_{y}}$

$c_{x}$ is the element amount content of the "unknown" sample $\left[\mathrm{mol} \mathrm{g}^{-1}\right], C_{y}$ is the element amount content of the spike $\left[\mathrm{mol} \cdot \mathrm{g}^{-1}\right], m_{x}$ is the mass of the sample $[\mathrm{g}], m_{y}$ that of the spike [g], and $R_{x}, R_{y}$ and $R_{b}$ are the isotope amount ratios of the sample (unspiked) [mol•mol$\left.{ }^{-1}\right]$, the spike and the blend, respectively. The $\Sigma\left(R_{i}\right)_{x}$ and $\Sigma\left(R_{i}\right)_{y}$ are the sums of all isotope amount ratios in the sample and spike, respectively.

\section{Results and discussion}

\section{Verification measurements of QC solutions}

The amount contents $\left[\mathrm{mol} \mathrm{g}^{-1}\right.$ ] of ${ }^{235} \mathrm{U}$ and ${ }^{239} \mathrm{Pu}$ of the QC solutions were determined using the equations below:

$$
\begin{aligned}
& c_{235_{U}}=\frac{m_{U C R M 116 A} \cdot \rho_{U C R M 116 A}}{M_{U} \cdot m_{U s o l}} \cdot f_{235_{U}} \cdot f_{\text {Uevap }} \\
& c_{239_{P u}}=\frac{m_{P U N B L 126} \cdot \rho_{\text {PuNBL126 }}}{M_{P u} \cdot m_{\text {Pusol }}} \cdot f_{239_{P u}} \cdot f_{\text {Puevap }}
\end{aligned}
$$


$m_{U C R M 116 A}, m_{P U N B L 126}, m_{U s o l}, m_{P u s o l}$ are the masses of the U CRM 116-A, Pu NBL 126 metals and the nitrate solutions [g], respectively; $\rho_{U C R M 116-A}$ and $\rho_{P U N B L 126}$ are the purities of the U CRM 116-A and Pu NBL 126 metals [ $\mathrm{g} \mathrm{g}^{-1}$ ], respectively; $M_{U}$ and $M_{P u}$ are the molar masses of $\mathrm{U}$ and $\mathrm{Pu}$ [g $\left.\mathrm{mol}^{-1}\right]$. The $f_{235_{U}}$ and $f_{239_{P u}}$ are the isotope amount fractions (e.g. abundances) of ${ }^{235} \mathrm{U}$ and ${ }^{239} \mathrm{Pu}$ in the solutions, respectively and $f_{\text {Uevap }}$ and $f_{\text {Puevap }}$ are the evaporation factors of the uranium and plutonium solutions, respectively. The values from gravimetric preparation of $\mathrm{U}$ and $\mathrm{Pu} \mathrm{QC}$ solutions are shown in Table 1.

The masses of the metals and the solutions were determined by substitution weighing and corrected for air buoyancy (as described previously in the section Metrological Weighing). Mass standards of class E2 (calibrated against class E1 standards) were used. The traceability of the masses from the substitution weighing to the SI is established through the class E1 mass standards, certified by the Belgian metrology institute (FOD Economie, Kwaliteit en Veiligheid, Metrologie). The major uncertainty contributions in substitution weighing come from the mass standards (calibration certificate), repeatability of the weighing sequence (SUUS) and the balance. Other contributions, such as the density of the air, metal and solution are negligible.

The values for the purity of the metals, the abundances and associated uncertainties were taken from the metal certificates. Atomic masses of the isotopes and half-lives for decay correction were obtained from the literature [32-34].

Table 1 Amount contents and mass fractions of ${ }^{235} \mathrm{U}$ and ${ }^{239} \mathrm{Pu}$ in QC solutions

\begin{tabular}{ll}
\hline & Gravimetric values $^{(\mathrm{a})}$ \\
\hline$c\left(^{235} \mathrm{U}\right)\left[\mu \mathrm{mol} \mathrm{g}{ }^{-1}\right.$ solution] & $12.8155(51)$ \\
$c\left(^{239} \mathrm{Pu}\right)\left[\mu \mathrm{mol} \mathrm{g}^{-1}\right.$ solution] ${ }^{(\mathrm{b})}$ & $7.0927(20)$ \\
$\gamma\left({ }^{235} \mathrm{U}\right)\left[\mathrm{mg} \mathrm{g}^{-1}\right.$ solution] ${ }^{(\mathrm{c})}$ & $3.0122(12)$ \\
$\gamma\left({ }^{239} \mathrm{Pu}\right)\left[\mathrm{mg} \mathrm{g}^{-1}\right.$ solution] ${ }^{(\mathrm{b}),(\mathrm{c})}$ & $1.69553(49)$ \\
\hline
\end{tabular}

${ }^{(a)}$ Expanded uncertainties $(k=2)$ are shown in parenthesis ${ }^{(b)}$ Values

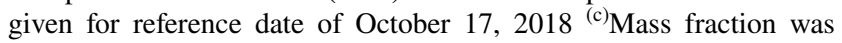
obtained using the equation $\gamma=c \cdot M$.
The evaporation factor $\left(f_{\text {evap }}\right)$ was determined by monitoring the weight of the flask before the dispensing of the solution into ampoules.

The individual uncertainties of all the input quantities were combined using the software GUM Workbench ${ }^{\odot}[8]$ to result in one combined standard uncertainty $\left(u_{\mathrm{c}}\right)$. A coverage factor of $k=2$ (95\% confidence interval) was applied to obtain the expanded uncertainty $\left(U=k \cdot u_{\mathrm{c}}\right)$. An example of the uncertainty budget for the gravimetric preparation of the U QC solution is shown in Table 2.

\section{Verification measurements of QC solutions}

Since only the ${ }^{239} \mathrm{Pu}$ atom fraction was originally certified in NBL-126 metal and the Pu isotope ratios were given as informative values only (i.e. without uncertainties), measurements of isotope ratios of the $\mathrm{Pu}$ QC solution were performed on a purified aliquot by TIMS. The results of the $\mathrm{Pu}$ isotope ratios are summarised in Table 3.

The isotope ratios measured in the $\mathrm{Pu} \mathrm{QC}$ solution agreed with the values from the certificate and with the results published by Byerly et al. [18]. The exception was the $n\left({ }^{238} \mathrm{Pu}\right) / n\left({ }^{239} \mathrm{Pu}\right)$ ratio, where a higher value was obtained in the TIMS measurement. This was most likely due to isobaric interferences with residual ${ }^{238} \mathrm{U}$ in the $\mathrm{Pu}$ fraction caused by insufficient purification of the uranium impurities present initially in the NBL 126 CRM metal. However, it was verified using both the full IDMS equation (Eq. 1 [15]) and a simplified IDMS equation for the isotope of interest only [30], that the $n\left({ }^{238} \mathrm{Pu}\right) / n\left({ }^{239} \mathrm{Pu}\right)$ ratio had no influence on the IDMS results of the ${ }^{239} \mathrm{Pu}$ and $\mathrm{Pu}$ amount and mass contents. Most of the IDMS results for ${ }^{239} \mathrm{Pu}$ amount contents, presented in this paper, were then determined using the simplified IDMS equation [30].

Verification measurements of the ${ }^{239} \mathrm{Pu}$ amount content in the $\mathrm{Pu} \mathrm{QC}$ solution (before dispensing) were carried out by IDMS using two ${ }^{242} \mathrm{Pu}$ spike materials, the $\mathrm{Pu}$ KRI-RM2 and the mixed ${ }^{242} \mathrm{Pu} /{ }^{233} \mathrm{U}$ IRMM-046c spike. The latter has been successfully used in various projects, including the certification of IRMM-1027 series LSD
Table 2 Simplified uncertainty budget for the ${ }^{235} \mathrm{U}$ amount content of the U QC solution

\begin{tabular}{|c|c|c|c|c|c|}
\hline Quantity & Value & Standard uncertainty & Unit & Type A/B & Contribution \\
\hline$m_{\mathrm{U}}^{(\mathrm{a})}$ & 1.1392700 & $35 \cdot 10^{-6}$ & $\mathrm{~g}$ & B & $2.4 \%$ \\
\hline$m_{\mathrm{sol}}^{(\mathrm{a})}$ & 352.4300 & 0.0200 & $\mathrm{~g}$ & B & $8.3 \%$ \\
\hline$\eta_{\mathrm{U}}^{(\mathrm{b})}$ & 0.9994500 & $58.3 \cdot 10^{-6}$ & $\mathrm{~g} \mathrm{~g}^{-1}$ & B & $8.8 \%$ \\
\hline$M_{\mathrm{U}}^{(\mathrm{b})}$ & 235.1857200 & $55 \cdot 10^{-6}$ & $\mathrm{~g} \mathrm{~mol}^{-1}$ & B & $0 \%$ \\
\hline$f_{235 \mathrm{U}^{(\mathrm{b})}}$ & 0.932547 & $19.0 \cdot 10^{-6}$ & $\mathrm{~mol} \mathrm{~mol}^{-1}$ & B & $0.9 \%$ \\
\hline$f_{\text {evap }}^{(\mathrm{a})}$ & 1.00037 & $350 \cdot 10^{-6}$ & & B & $79.5 \%$ \\
\hline$c_{235 \mathrm{U}}$ & $12.8155 \cdot 10^{-6}$ & $2.53 \cdot 10^{-9}$ & $\mathrm{~mol} \mathrm{~g}^{-1} \mathrm{sol}$ & & \\
\hline
\end{tabular}

(a) as determined from weighing and measurements (JRC-Geel G.2 laboratory's data) ${ }^{\text {(b) }}$ as from certificate of CRM 116-A material (NBL certificate) 
Table 3 Results of the isotope amount ratio measurements of the Pu QC solution

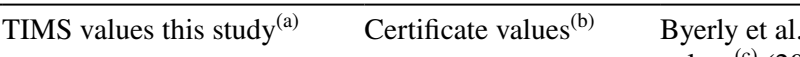
values $^{(c)}(2016)$

\begin{tabular}{llll}
\hline$n\left({ }^{238} \mathrm{Pu}\right) / n\left({ }^{239} \mathrm{Pu}\right)\left[\mathrm{mol} \mathrm{mol}^{-1}\right]$ & $0.0000342(27)$ & 0.0000126 & $0.0000200(15)$ \\
$n\left({ }^{240} \mathrm{Pu}\right) / n\left({ }^{239} \mathrm{Pu}\right)\left[\mathrm{mol} \mathrm{mol}^{-1}\right]$ & $0.020920(08)$ & 0.020953 & $0.020920(09)$ \\
$n\left({ }^{241} \mathrm{Pu}\right) / n\left({ }^{239} \mathrm{Pu}\right)\left[\mathrm{mol} \mathrm{mol}^{-1}\right]$ & $0.0000340(11)$ & 0.0000322 & $0.0000349(01)$ \\
$n\left({ }^{242} \mathrm{Pu}\right) / n\left({ }^{239} \mathrm{Pu}\right)\left[\mathrm{mol} \mathrm{mol}^{-1}\right]$ & $0.0000082(21)$ & 0.0000102 & $0.0000101(01)$ \\
$n\left({ }^{239} \mathrm{Pu}\right) / n(\mathrm{Pu})[\%]$ & $97.9436(08)$ & $97.9425(01)$ & $97.9446(09)$ \\
\hline
\end{tabular}

${ }^{(a)}$ Reference date for all values in Table: October 17, $2018{ }^{\text {(b) }}$ NBL-126 metal certificate values decayed from October 1, 1985 to reference date ${ }^{(c)}$ Byerly et al. (2016) [18] values decayed from October 28, 2013 to reference date. Expanded uncertainties $(k=2)$ are shown in parenthesis spikes (Large Size Dried spike) [24, 35, 36], the verification of the IAEA LSD SAL (Safeguard Analytical Laboratory) [37] and in external proficiency testing (IAEA Round Robin and the CEA/CETAMA EQRAIN). The Pu KRIRM2 was used to verify the ${ }^{239} \mathrm{Pu}$ amount content of the QC sample since it was successfully used as well by the IAEA-NML (Nuclear Material Laboratory) in verification measurements of the IRMM-1027r LSD spike [37].

The IDMS results for the $\mathrm{Pu}$ QC solution in the original flask (before dispensing) are shown in Fig. 1. They are expressed as the relative difference (bias in \%) from the assigned value of the gravimetric preparation.

A good agreement between all IDMS results was obtained. The second data set (with Pu KRI-RM2 spike, in 2018) showed a slightly higher bias (a relative difference of $+0.15 \%$ ) from the gravimetric value when compared to the other results. The reason for this observation could not be found. Such a positive bias when using the Pu KRI RM2 spike, was also observed during the verification measurements of the IRMM-1027r LSD spike [37]. Nevertheless, the agreement between the gravimetric value and the IDMS results using the two different spikes was fit for purpose for a QC sample to verify the Pu amount content in the solution. It can be observed that all uncertainties were in the same range.

Measurements of the $\mathrm{U}$ isotope ratios of the U QC solution were similarly carried out and are summarised in Table 4. All the measured $U$ isotope ratios agreed with the values from the certificate.

Verification of the $\mathrm{U}$ amount content in the U QC solution in the original flask (before dispensing) was performed using two uranium certified test items, namely EQRAIN 15U (R056) and EQRAIN 16U (T050) in the scope of the EQRAIN proficiency tests (PT) by CEA/
Fig. 1 Deviations of IDMS results to the ${ }^{239} \mathrm{Pu}$ gravimetric value in $\mathrm{Pu} \mathrm{QC}$ solution. Error bars show the relative expanded uncertainties $(k=2)$ of the measurement results. Red dotted lines show the relative expanded uncertainty $(k=2)$ of the gravimetric value set as the reference of $0 \%$ (red line), in the different dispensed aliquots from the original flask (before dispensing in ampoules). Due to the change in the evaporation correction for each set of measurements, the uncertainties associated with the gravimetric value became larger with time

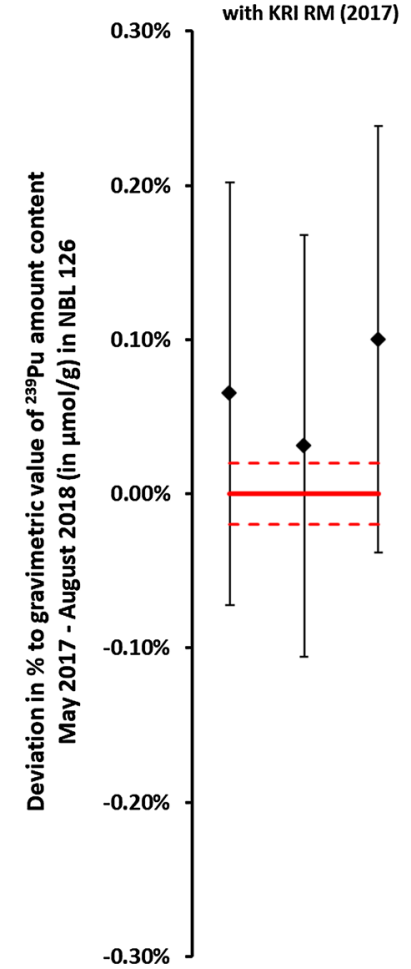

with IRMM-046c

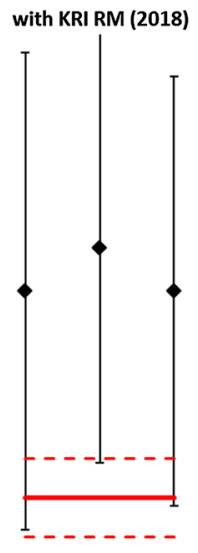

NBL-126 IDMS values
- NBL-126 gravimetric value
--- Unc on gravimetric value $k=2$

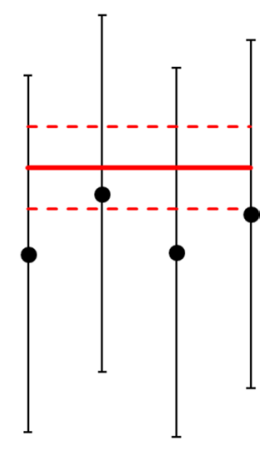


Table 4 Results of the isotope amount ratios measurements of the U QC solution

\begin{tabular}{|c|c|c|}
\hline & Certified values & $\begin{array}{l}\text { TIMS values this } \\
\text { study }^{(a)}\end{array}$ \\
\hline $\begin{array}{l}n\left({ }^{233} \mathrm{U}\right) / n\left({ }^{235} \mathrm{U}\right)[\mathrm{mol} / \\
\mathrm{mol}]\end{array}$ & $0.0000003863(86)$ & n.a \\
\hline $\begin{array}{l}n\left({ }^{234} \mathrm{U}\right) / n\left({ }^{235} \mathrm{U}\right)[\mathrm{mol} / \\
\mathrm{mol}]\end{array}$ & $0.0115836(97)$ & $0.0115893(20)$ \\
\hline $\begin{array}{l}n\left({ }^{236} \mathrm{U}\right) / n\left({ }^{235} \mathrm{U}\right)[\mathrm{mol} / \\
\mathrm{mol}]\end{array}$ & $0.0094713(77)$ & $0.0094716(59)$ \\
\hline $\begin{array}{l}n\left({ }^{238} \mathrm{U}\right) / n\left({ }^{235} \mathrm{U}\right)[\mathrm{mol} / \\
\mathrm{mol}]\end{array}$ & $0.051277(41)$ & $0.051264(19)$ \\
\hline
\end{tabular}

(a) as measured by TIMS/TE on June 24, 2020. Expanded uncertainties $(k=2)$ are shown in parenthesis.

CETAMA, as well as the external ${ }^{233} \mathrm{U}$ spike, U KRI-RM1. This latter was also used as spike and inter-linked with the second ampoule of EQRAIN 16U at JRC-Geel G.2 (T100 ampoule) and at the IAEA-NML.

In Fig. 2, it can be seen that the IDMS results with EQRAIN 15U (R056) and EQRAIN 16U (T050) confirmed the QC sample gravimetric value. However, a positive bias was obtained when verifying the $U$ amount content of the QC sample with the U KRI-RM1 spike. A similar positive bias, although smaller (i.e. $+0.05 \%$ ), was observed both at JRC-Geel G.2 and at the IAEA-NML when using this spike on the second set of EQRAIN 16U (personal communication).
Among the U QC samples analysed with IRMM-046c spike, two IDMS results were in agreement within the uncertainties with the gravimetric value, whereas the two first measurement results (as shown in Fig. 2) did not agree with the rest of the IDMS results. Both results have similar biases but are much lower than the other results. Moreover, it can be observed that the measurement uncertainties of IRMM$046 \mathrm{c}$ results are smaller (by a factor of two to three) compared to the other spikes used in this verification.

In general, these IDMS results agreed well within uncertainties among one another and with the gravimetric value (Fig. 2) and therefore considered fit for purpose for a QC sample to verify the $\mathrm{U}$ amount content in the solution.

Finally, both QC samples were verified successfully with the JRC-Geel G.2 CRM, IRMM-046c, with the proficiency test items (with the EQRAIN 15U and EQRAIN 16U) and the external Pu and U KRI-RM-2 and -1 spikes, respectively. However, with the KRI-RM-1 and -2 spikes some slight positive biases were observed in the IDMS results (Figs. 1 and 2), also when inter-linked with IRMM-1027r [37] and the most recent EQRAIN 16U. These IDMS results and spike CRMs will be part of the continuous in-house campaign on inter-linking JRC-Geel G.2's and external spike CRMs, during which possible biases will be investigated.

\section{Uncertainty in IDMS measurements}

An example of the uncertainty calculation for the determination of the ${ }^{235} \mathrm{U}$ amount content by IDMS in the U QC
Fig. 2 Deviations of IDMS results to the ${ }^{235} \mathrm{U}$ gravimetric value in $U$ QC solution. Error bars show the relative expanded uncertainties $(k=2)$ of the measurement results. Red dotted lines show the relative expanded uncertainty $(k=2)$ of the gravimetric value, set as the reference of $0 \%$ (red line), in the different dispensed aliquots from the original flask (before dispensing in ampoules). Due to the change in the evaporation correction for each set of measurements, the uncertainties associated with the gravimetric value became larger with time

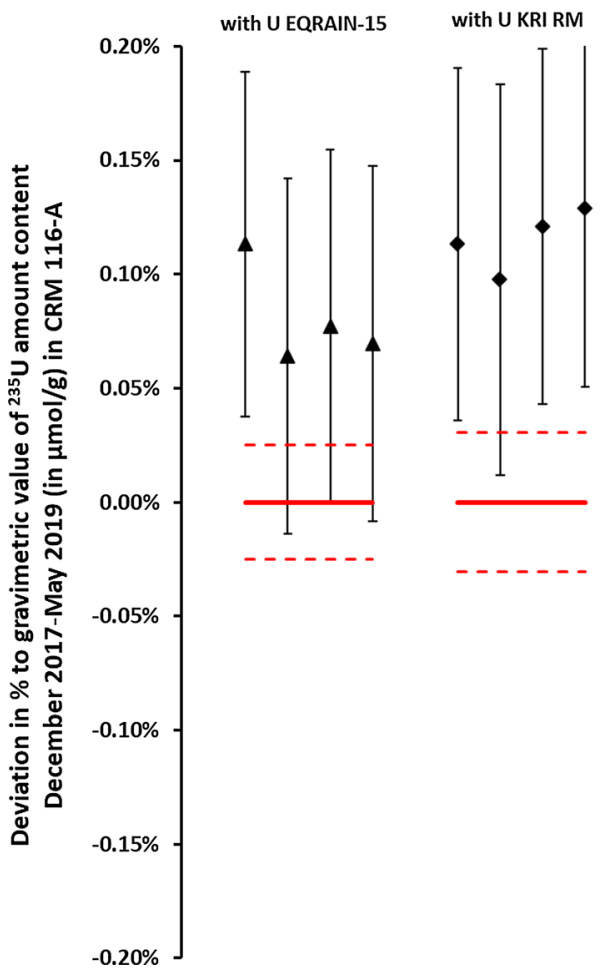

with U EQRAIN-16

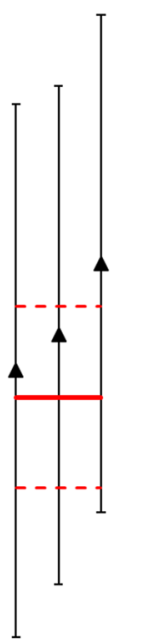

- IDMS results CRM-116A CRM 116-A gravimetric value - - - Unc on grav value $k=2$ 
solution using IRMM-046c spike is given below. The general Eq. (1) for IDMS can be rearranged to determine the ${ }^{235} \mathrm{U}$ amount content rather than the total $\mathrm{U}$ amount content as follows [30]: obtained from the certificate of CRM 116-A as described in Table 4 and, therefore treated as Type B components.

Uncertainties associated with the weighing were discussed in the previous section.

$c_{\mathrm{x}}\left({ }^{235} U\right)=c_{\mathrm{y}}\left({ }^{233} U\right) \cdot \frac{m_{y}}{m_{x}} \cdot \frac{\left.R_{\mathrm{y}}{ }^{233} U /{ }^{235} U\right)-R_{\mathrm{b}}\left({ }^{233} U /{ }^{235} U\right) \cdot K}{R_{\mathrm{b}}\left({ }^{233} U / 235 U\right) \cdot K-R_{\mathrm{x}}\left({ }^{233} U / 235 U\right)} \cdot \frac{1}{R_{\mathrm{y}}\left({ }^{233} U /{ }^{235} U\right)}$

$c_{X}\left({ }^{235} \mathrm{U}\right)$ is the amount content $\left[\mathrm{mol} \mathrm{g}^{-1}\right]$ of the ${ }^{235} \mathrm{U}$; $\left.c_{y}{ }^{233} \mathrm{U}\right)$ and $R_{\mathrm{y}}\left({ }^{233} U /{ }^{235} U\right)$ are the ${ }^{233} \mathrm{U}$ amount content and the isotope amount ratio of the spike, respectively; $m_{x}$ and $m_{y}$ are the masses of the sample and the spike [g], respectively; $R_{\mathrm{x}}\left({ }^{233} U /{ }^{235} U\right)$ and $R_{\mathrm{b}}\left({ }^{233} U /{ }^{235} U\right)$ are the isotope amount ratios of the sample and the blend, respectively; $\mathrm{K}$ is the mass bias correction factor $\left[\mathrm{mol} \mathrm{mol}{ }^{-1}\right]$.

The use of the simplified Eq. (4) is advantageous because not all the isotopes ratios need to be known or measured. Other equations are possible depending on the spike used and how the ratios are expressed [30].

The blend ratio $\left(R_{\mathrm{b}}\right)$ is determined by replicate measurements, usually between three and four per blend. The variability, i.e. the standard uncertainty associated with the mean is incorporated into the uncertainty estimation as Type A.

Corrections for mass fractionation are applied to the isotope ratios. This is determined by repeated measurements (between four and six replicates) of a standard with a well-characterised and known isotopic composition (e.g. IRMM-074/10), which is measured together with the samples under the same conditions (e.g. approximately the same amount and ratio as in the samples). The isotopic standards are measured before and after the samples (i.e. bracketing).

The calculated $K$-factor $\left(K=\frac{R_{\text {cert }}}{R_{\text {meas }}}\right)$ is used to correct for mass fractionation for the equivalent isotope ratio in the samples. The uncertainty associated with the mass fractionation consists of two components, the repeatability of the measurement of the isotopic standard (Type A) and the uncertainty of the certified isotope ratio from the certificate (Type B). An additional uncertainty component $\left(\delta_{\mathrm{TE}}\right)$ (on an input quantity value of zero) associated with the total evaporation method is introduced as described in Richter et al. [38]. This accounts for possible deviations due to different effects from solution preparation or running conditions between a sample and the standard used for mass fractionation correction.

The amount content, $c_{\mathrm{y}}\left({ }^{233} U\right)$ the isotope ratio of the spike CRM $\left(R_{\mathrm{y}}\left({ }^{233} U /{ }^{235} U\right)\right.$ and their associated uncertainties are taken from the spike CRM certificate (Type B).

In our case for the $\mathrm{U} Q \mathrm{QC}$ solution, the isotope ratio of the sample $\left(R_{\mathrm{x}}\left({ }^{233} U /{ }^{235} U\right)\right.$ and associated uncertainty were
The uncertainty budget for the determination of the ${ }^{235} \mathrm{U}$ amount content in the U QC solution using IRMM-046c spike is shown in Table 5.

All individual uncertainty components were combined using GUM Workbench ${ }^{\odot}$ [8]. A coverage factor of $k=2$ (confidence interval of 95\%) was applied for the calculation of all the expanded uncertainties. However, different $k$ values can be applied depending on the effective degrees of freedom and the desired confidence interval.

In Table 5, it can be observed that for an IDMS measurement result for uranium, the major component to the combined standard uncertainty comes from the spike amount content ( $c_{\mathrm{y}}$, IRMM-046c), followed by the measured blend ratio $R_{b}$. The ID-TIMS uncertainty $\delta_{\mathrm{TE}}$ contributes as well, but to a lesser extent, followed by the contribution of the isotopic standard ( $\left.R_{074 / 10 \text {,meas }}, R_{074 / 10 \text { cert }}\right)$ used for the correction of mass fractionation.

Another example of the uncertainty budget for the determination of ${ }^{239} \mathrm{Pu}$ in the $\mathrm{Pu}$ QC solution using the IRMM046c spike is shown in Table 6. In this example, the dominant component of uncertainty comes from the isotopic standard $R_{290 \mathrm{~b} / \mathrm{A} 3 \text {,cert }}$, followed by the uncertainty of the amount content of the spike $\left(c_{\mathrm{y}}\right)$.

In Fig. 2, the IDMS measurement results of ${ }^{235} \mathrm{U}$ amount content of the U QC solution with the EQRAIN 15U (R056) on four blends are represented. These blends are measured

Table 5 Uncertainty budget for ${ }^{235} \mathrm{U}$ amount content by IDMS with ${ }^{233} \mathrm{U}$ spike (IRMM-046c)

\begin{tabular}{lllll}
\hline Quantity & Unit & Type A/B & $\begin{array}{l}\text { Contribution } \\
\text { QC1 }\end{array}$ & $\begin{array}{l}\text { Contribution } \\
\text { QC4 }\end{array}$ \\
\hline$m_{\mathrm{x}}$ & $\mathrm{g}$ & $\mathrm{B}$ & $4.5 \%$ & $11.7 \%$ \\
$m_{\mathrm{y}}$ & $\mathrm{g}$ & $\mathrm{B}$ & $1.1 \%$ & $2.2 \%$ \\
$c_{\mathrm{y}}$ & $\mathrm{mol} \mathrm{g}^{-1}$ & $\mathrm{~B}$ & $35.6 \%$ & $35.9 \%$ \\
$R_{\mathrm{y}}$ & $\mathrm{mol} \mathrm{mol}^{-1}$ & $\mathrm{~B}$ & $0 \%$ & $0 \%$ \\
$R_{\mathrm{x}}$ & $\mathrm{mol} \mathrm{mol}^{-1}$ & $\mathrm{~B}$ & $0 \%$ & $0 \%$ \\
$R_{074 / 10, \text { cert }}$ & $\mathrm{mol} \mathrm{mol}^{-1}$ & $\mathrm{~B}$ & $7.1 \%$ & $7.1 \%$ \\
$R_{074 / 10, \mathrm{meas}}$ & $\mathrm{mol} \mathrm{mol}^{-1}$ & $\mathrm{~A}$ & $9.8 \%$ & $6.9 \%$ \\
$R_{\mathrm{b}}$ & $\mathrm{mol} \mathrm{mol}^{-1}$ & $\mathrm{~A}$ & $29.3 \%$ & $23.6 \%$ \\
$\delta_{\mathrm{TE}}$ & & $\mathrm{B}$ & $12.6 \%$ & $12.7 \%$ \\
$c_{\mathrm{x}}$ & $\mathrm{mol} \mathrm{g}^{-1} \mathrm{sol}$ & & $0.038 \%{ }^{(\mathrm{a})}$ & $0.037 \%(\mathrm{a})$ \\
\hline
\end{tabular}

${ }^{(a)}$ Relative expanded uncertainty $(k=2)$. 
Table 6 Uncertainty budget for ${ }^{239} \mathrm{Pu}$ amount content by IDMS with ${ }^{242} \mathrm{Pu}$ spike (IRMM-046c)

\begin{tabular}{lllll}
\hline Quantity & Unit & Type A/B & Contribution QC1 & Contribution QC4 \\
\hline$m_{\mathrm{x}}$ & $\mathrm{g}$ & $\mathrm{B}$ & $1.8 \%$ & $2.2 \%$ \\
$m_{\mathrm{y}}$ & $\mathrm{g}$ & $\mathrm{B}$ & $0.1 \%$ & $0.2 \%$ \\
$c_{\mathrm{y}}$ & $\mathrm{mol} \mathrm{g}^{-1}$ & $\mathrm{~B}$ & $13.4 \%$ & $14.0 \%$ \\
$R_{\mathrm{y}}$ & $\mathrm{mol} \mathrm{mol}^{-1}$ & $\mathrm{~B}$ & $0 \%$ & $0 \%$ \\
$R_{\mathrm{x}}$ & $\mathrm{mol} \mathrm{mol}^{-1}$ & $\mathrm{~B}$ & $0 \%$ & $0 \%$ \\
$R_{290 \mathrm{~b} / \mathrm{A} 3 \text {, cert }}$ & $\mathrm{mol} \mathrm{mol}^{-1}$ & $\mathrm{~B}$ & $74.8 \%$ & $78.5 \%$ \\
$R_{290 \mathrm{~b} / \mathrm{A} 3 \text {,meas }}$ & $\mathrm{mol} \mathrm{mol}^{-1}$ & $\mathrm{~A}$ & $1.9 \%$ & $1.6 \%$ \\
$R_{\mathrm{b}}$ & $\mathrm{mol} \mathrm{mol}^{-1}$ & $\mathrm{~A}$ & $5 \%$ & $0.3 \%$ \\
$\delta_{\mathrm{TE}}$ & & $\mathrm{B}$ & $3 \%$ & $3.2 \%$ \\
$c_{\mathrm{x}}$ & $\mathrm{mol} \mathrm{g}^{-1} \mathrm{sol}$ & & $0.12 \%$ (a) $^{(\mathrm{a})}$ & $0.11 \%$ \\
\hline
\end{tabular}

${ }^{(a)}$ Relative expanded uncertainty $(k=2)$ under repeatability conditions. Performing measurements on several independent blends enables the analyst to evaluate the between-blends variability and to check for any possible inconsistency. If the measurement process is under control, there should not be any (significant) difference between the blend IDMS results.

There are different ways to check the between-blend effect under repeatability conditions. In our laboratory, we apply the approach of consistency check as described by Kessel et al. [39]. In this approach, a numerical equivalence check is done on the results of the blends by comparing the difference (noted $\varepsilon$ ) of each single blend value with the arithmetic mean value of the blends to the combined standard uncertainty of this difference $u(\varepsilon)$, as shown in Eq. (5).

$|\varepsilon| \leq k \cdot u(\varepsilon) \quad$ (usuallyk $=2$ )

where $\varepsilon=\left|Y_{i}-\bar{Y}\right|$, with $Y_{\mathrm{i}}$ the single blend value, $\bar{Y}$ the arithmetic mean value of all the blends and $u(\varepsilon)=u\left(Y_{i}-\bar{Y}\right)$ the standard uncertainty of the difference $(\varepsilon)$.

All blends must meet this condition. If the test fails, there is an implication of an unknown effect between the blends. In this case, to cover for the possible between-blend effect and thereby enabling the condition to be met, an additional term $(\delta)$ is introduced to each blend value, with an expected value of zero and a standard uncertainty (noted $u(\delta))$ identical for all blend values.

An example of the use of this consistency check and of the additional term for between-blend effect $(\delta)$ on the uncertainty budget for the ${ }^{235} \mathrm{U}$ amount content in the four blends of the U QC solution using the EQRAIN 15U (R056) is shown in Table 7.

In this example, an additional uncertainty $u\left(\delta_{1-4}\right)$ of 1.20 $\times 10^{-9}$ was added to each blend value to cover the possible between-blend effects (total contribution to uncertainty on ${ }^{235} \mathrm{U}$ amount content of $2 \%$ ). As observed already in Table 5, the largest uncertainty contribution came from the spike $\left(c_{y}\right)$, followed by the isotopic standard for mass fractionation correction $\left(R_{074 / 10 \text {,meas }}\right.$ and $\left.R_{074 / 10 \text {, cert }}\right)$ and the $\delta_{\mathrm{TE}}$.

It can be seen that reducing the uncertainty of IDMS results will, in many cases be limited by the uncertainty of the spikes and isotopic standards for mass fractionation. Further improvement, can be achieved by performing double IDMS, which means additional in-house spike preparation and characterisation [13, 40].

\section{Quality control (QC) charts}

Control charts [12] were established using the IDMS QC samples to monitor the performance of the $\mathrm{Pu}\left(\right.$ e.g. $\left.{ }^{239} \mathrm{Pu}\right)$ and $U$ measurements (e.g. $\left.{ }^{235} \mathrm{U}\right)$ under intermediate measurement conditions (i.e. changes with time, changes of instrument calibration and of operators within the laboratory, etc.) in compliance with ISO 17,025 [1]. In Fig. 3 and Fig. 4, two examples of QC charts for the ${ }^{239} \mathrm{Pu}$ and for the ${ }^{235} \mathrm{U}$ IDMS respectively are shown.

Since their validation, both IDMS QC samples have been measured on a regular basis (almost every two-three months) in various projects, in particular in certification campaigns and in external quality assessments (e.g. PT, ILC). They underwent the same analytical procedures as the other samples, including weighing/spiking, chemical treatment and isotope measurements, but at different intervals of time over a long period (i.e. under intermediate measurement conditions).

In Fig. 3, the blue line represents the tolerance limit of $0.1 \%$ of the control charts for the relative difference between the measured and the assigned (gravimetric) value. This tolerance limit was chosen based on the evolution of the JRC Geel's IDMS results in external PT and ILC over the years. If some data points would fall outside this tolerance limit of $0.1 \%$, the IDMS analyses of the sample(s) concerned would be repeated and possible causes investigated [12].

The RSD of all the IDMS data for the $\mathrm{Pu}$ QC sample (before and after dispensing, Fig. 1 and Fig. 3) is $0.054 \%$ 
Table 7 Uncertainty budget for ${ }^{235} \mathrm{U}$ amount content (IDMS with EQRAIN 15U, ${ }^{238} \mathrm{U}$ spike)

\begin{tabular}{|c|c|c|c|c|c|}
\hline Quantity & Value & Standard uncertainty & Unit & Type A/B & $\begin{array}{l}\text { Contribution } \\
(\%)\end{array}$ \\
\hline$m_{\mathrm{x} 1}$ & 2.00560 & $5.00 \times 10^{-5}$ & $\mathrm{~g}$ & $\mathrm{~B}$ & 0 \\
\hline$m_{\mathrm{x} 2}$ & 1.99231 & $8.50 \times 10^{-5}$ & $\mathrm{~g}$ & $\mathrm{~B}$ & 0.1 \\
\hline$m_{\mathrm{x} 3}$ & 2.01373 & $8.00 \times 10^{-5}$ & $\mathrm{~g}$ & B & 0 \\
\hline$m_{\mathrm{x} 4}$ & 2.01425 & $7.00 \times 10^{-5}$ & $\mathrm{~g}$ & B & 0 \\
\hline$m_{\mathrm{y} 1}$ & 0.68806 & $8.00 \times 10^{-5}$ & $\mathrm{~g}$ & B & 0.8 \\
\hline$m_{\mathrm{y} 2}$ & 0.47460 & $8.50 \times 10^{-5}$ & $\mathrm{~g}$ & B & 1.8 \\
\hline$m_{\mathrm{y} 3}$ & 0.50229 & $8.00 \times 10^{-5}$ & $\mathrm{~g}$ & B & 1.4 \\
\hline$m_{\mathrm{y} 4}$ & 0.49463 & $8.50 \times 10^{-5}$ & $\mathrm{~g}$ & B & 1.6 \\
\hline$R_{B I}$ & 0.08008382 & $6.48 \times 10^{-6}$ & $\mathrm{~mol} \mathrm{~mol}^{-1}$ & A & 0.4 \\
\hline$R_{B 2}$ & 0.11191274 & $8.35 \times 10^{-6}$ & $\mathrm{~mol} \mathrm{~mol}^{-1}$ & A & 0.4 \\
\hline$R_{B 3}$ & 0.10724388 & $4.73 \times 10^{-6}$ & $\mathrm{~mol} \mathrm{~mol}^{-1}$ & A & 0.1 \\
\hline$R_{B 4}$ & 0.10880240 & $6.82 \times 10^{-6}$ & $\mathrm{~mol} \mathrm{~mol}{ }^{-1}$ & A & 0.3 \\
\hline$c_{\mathrm{y}}$ & $5.1124 \times 10^{-4}$ & $5.00 \times 10^{-10}$ & $\mathrm{~mol} \mathrm{~g}^{-1}$ & B & 62.4 \\
\hline$R_{\mathrm{y}}{ }^{\text {(a) }}$ & $7.35 \times 10^{-5}$ & $1.15 \times 10^{-6}$ & $\mathrm{~mol} \mathrm{~mol}{ }^{-1}$ & A & 0 \\
\hline$R_{\mathrm{x}}$ & $3.8632 \times 10^{-7}$ & $4.30 \times 10^{-9}$ & $\mathrm{~mol} \mathrm{~mol}^{-1}$ & B & 0 \\
\hline$R_{074 / 10, \text { cert }}$ & 1.000259 & $7.50 \times 10^{-5}$ & $\mathrm{~mol} \mathrm{~mol}^{-1}$ & B & 5.0 \\
\hline$R_{074 / 10 \text {,meas }}$ & 1.000247 & $1.27 \times 10^{-4}$ & $\mathrm{~mol} \mathrm{~mol}^{-1}$ & A & 14.5 \\
\hline$\delta_{1}$ & 0.0 & $1.20 \times 10^{-9}$ & & B & 0.5 \\
\hline$\delta_{2}$ & 0.0 & $1.20 \times 10^{-9}$ & & B & 0.5 \\
\hline$\delta_{3}$ & 0.0 & $1.20 \times 10^{-9}$ & & B & 0.5 \\
\hline$\delta_{4}$ & 0.0 & $1.20 \times 10^{-9}$ & & B & 0.5 \\
\hline$\delta_{\mathrm{TE}}$ & 0.0 & $1.00 \times 10^{-4}$ & & B & 9.0 \\
\hline$c_{\mathrm{x}}$ & $12.8215 \times 10^{-6}$ & $4.30 \times 10^{-9}$ & $\mathrm{~mol} \mathrm{~g}^{-1}$ sol & & \\
\hline
\end{tabular}

${ }^{\text {(a) }} R_{\mathrm{y}}$ ratio of the EQRAIN $15 \mathrm{U}$ was determined by TIMS on one aliquot (not provided by CEA/CETAMA).

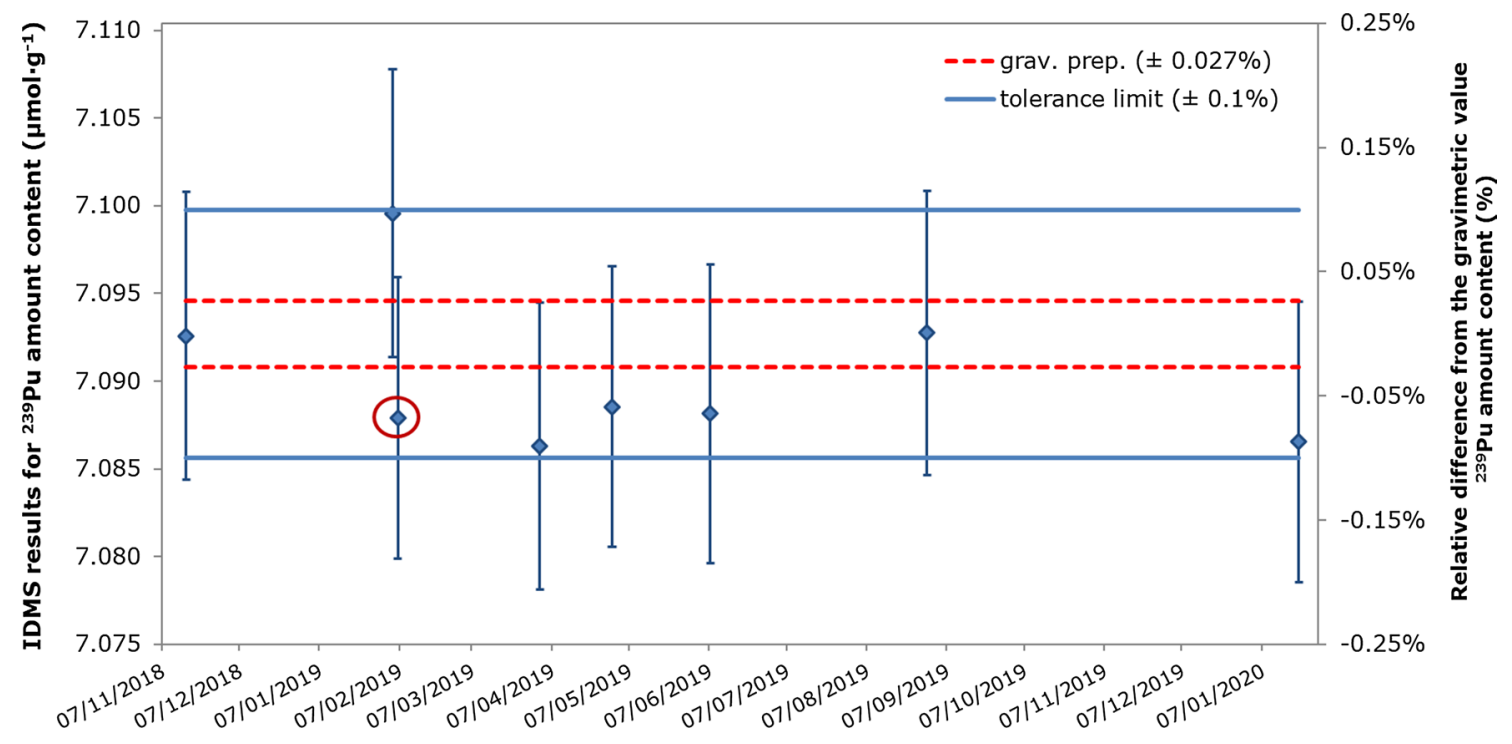

Fig. 3 Quality control chart for the ${ }^{239} \mathrm{Pu}$ amount content (in $\mu \mathrm{mol}$ $\mathrm{g}^{-1}$ ) by IDMS in Pu QC sample using IRMM-046c spike. The circled data point represents an IDMS measurement performed on a QC solution before the dispensing. Error bars show the expanded uncer- tainties $(k=2)$. The red dotted line represents the relative uncertainty $(k=2)$ of the gravimetric value. Blue line represents the tolerance limit of $0.1 \%$ (see text for details) 


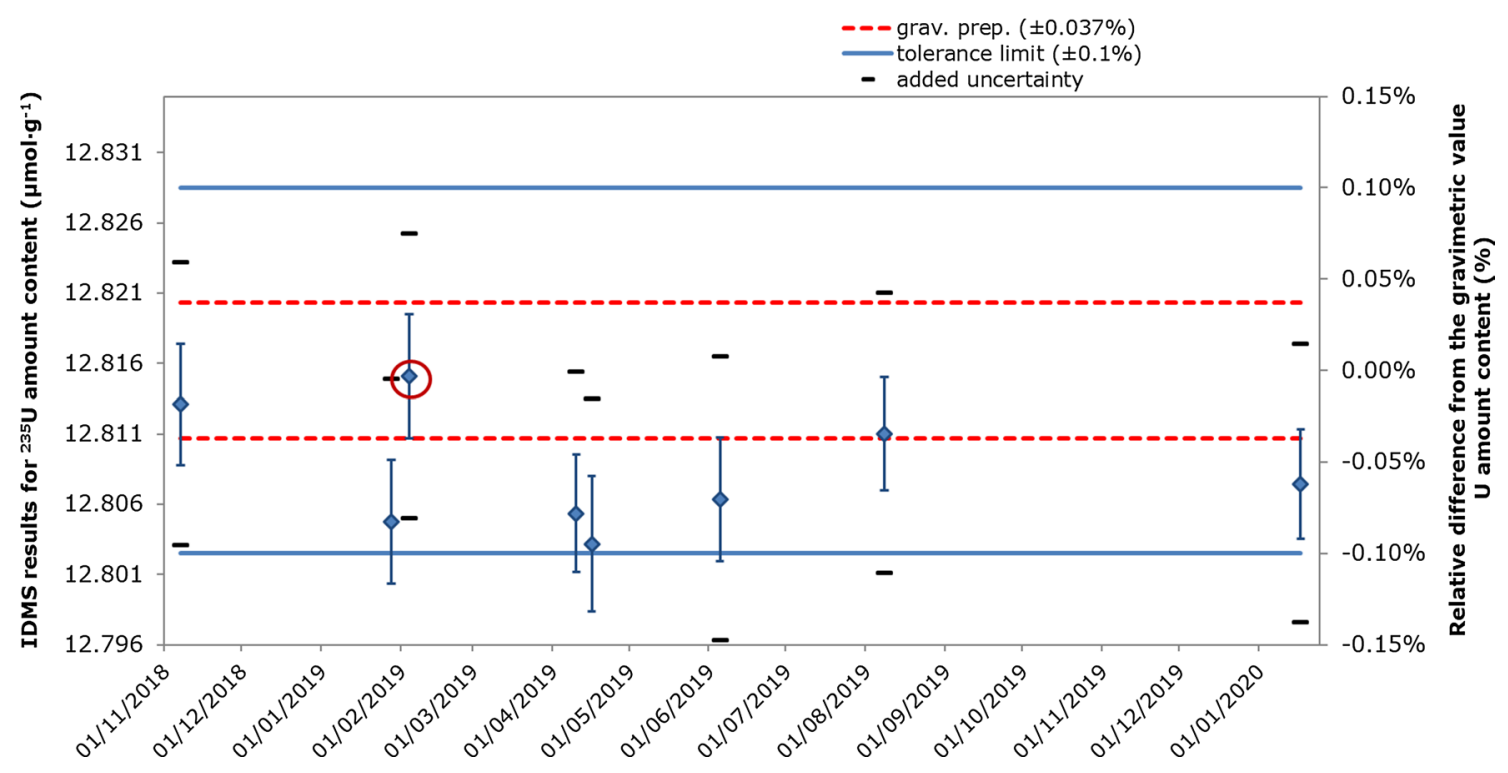

Fig. 4 Quality control chart for the measurement of the amount content (in $\mu \mathrm{mol} \mathrm{g} \mathrm{g}^{-1}$ ) of ${ }^{235} \mathrm{U}$ by IDMS using IRMM-046c. The circled data point represents an IDMS measurement performed on a QC solution before the dispensing. Error bars show the expanded uncertainties $(k=2)$. The red dotted line represents the relative uncertainty

(i.e. the tolerance limit corresponds here to ca. 2xRSD), while the RSD of all the IDMS data for the U QC sample (before and after dispensing, Figs. 1 and 4 ) is $0.035 \%$ (i.e. the tolerance limit corresponds here to ca. 3xRSD).

It can be seen in Fig. 3 that all the Pu IDMS results fall within the tolerance limit of $0.1 \%$, with two Pu IDMS results showing only a $-0.002 \%$ and a $0.004 \%$ bias from the gravimetric value. The average relative difference (bias) of all the results of all the analysed QC samples from the assigned value is $-0.031 \%$ (Fig. 3). Therefore, although there might be a slight negative bias arising from the Pu IDMS measurement of this QC sample using the IRMM-046c spike, all uncertainties associated with the Pu IDMS results are in the range of $0.11-0.12 \%(k=2)$, as also observed in Table 6, and are therefore fit for purpose.

The control chart for ${ }^{235} \mathrm{U}$ IDMS is shown in Fig. 4. Uncertainties associated with the U IDMS results are in the range of $0.030-0.037 \%(k=2)$, as also observed in Table 5 . The average relative difference from the assigned value is $-0.063 \%$, with the majority of the results below the assigned value, but all within the tolerance limit of $0.1 \%$. This may indicate the presence of a small systematic bias in the U IDMS results over time (intermediate measurement conditions). The source has not yet been identified and therefore could not be directly corrected for. However, this slight bias is already partly covered by the current uncertainties, since some of the U IDMS values overlap within the uncertainties with the gravimetric value (Fig. 4). $(k=2)$ of the gravimetric value. The error bars (black symbols) represent the uncertainty including the additional uncertainty on IDMS QC results. Blue line represents tolerance limit of $0.1 \%$ and the blue dotted error bars, the additional uncertainty (see text for details)

These uncertainties are also much smaller when compared to those of the Pu results (Fig. 3), which is mainly due to the smaller certified uncertainties for the spike (U amount content in IRMM-046c) and isotopic standard (IRMM-074/10) used for the U IDMS. Indeed, for the Pu IDMS, the isotopic standard is the dominant component to the uncertainty, and the uncertainty of the IRMM-290b/A3 (rel. $U=0.10 \%, k=2$ ) is ca. 6 times larger than the uncertainty of IRMM-074/10 (rel. $U=0.015 \%, k=2)$.

These observations have also been apparent from the JRC Geel's U IDMS results during external PTs and ILCs. Therefore, the uncertainties associated with U IDMS measurement might be underestimated. To account for these observations (smaller/underestimated uncertainties, possible small systematic bias), the first approach, described in this study, was to introduce an additional component of uncertainty in the IDMS budget on the $\mathrm{U}$ amount content based on the standard deviation of the U QC sample IDMS results.

For this purpose, a one-factor ANOVA (analysis of variance) was done on all the individual replicates of the eleven analysed U QC samples (i.e. 3 for each U QC sample). A between-QC variability of $0.034 \%$ and a within-QC variability of $0.010 \%$ were found. The between-QC standard deviation was then similar to the RSD of $0.035 \%$, i.e. the spread of all the IDMS data for the U QC sample (before and after dispensing). Therefore, it was decided to use the RSD of the U IDMS results of the QC sample as additional uncertainty to account for possible unknown effect on the U IDMS measurements under intermediate precision conditions. In 
the case of the U QC samples, this resulted in a final averaged relative expanded uncertainty of $0.08 \%(k=2)$ on the $\mathrm{U}$ amount content results, as reported in Fig. 4. This approach was then applied to a series of recent U IDMS measurements at JRC-Geel G.2 to make the uncertainty associated with U IDMS method more fit for purpose.

On the other hand, the JRC-Geel G.2 is investigating other ways of estimating the uncertainty of IDMS results, as for instance, performing the propagation of distributions of the uncertainty using the Monte Carlo Method (MCM) [41].

\section{Conclusion and outlook}

Through several examples of IDMS measurement results for the ${ }^{239} \mathrm{Pu}$ and ${ }^{235} \mathrm{U}$ amount contents, this paper gives insight on how IDMS measurement results and associated uncertainties are currently determined at the JRC-Geel G.2 using the software GUMWorkbench ${ }^{\odot}$ and based on the ISO "Guide to the Expression of Uncertainty in Measurement". This paper also highlights that the uncertainties of the $\mathrm{Pu}$ and U IDMS measurement results are dominated and therefore, quite often limited, by the uncertainties of the spikes used for isotope dilution and the uncertainties of the isotopic standards used for mass fractionation correction.

Moreover, two newly prepared IDMS QC samples for U and $\mathrm{Pu}$ were successfully validated and these results were integrated within the continuous inter-calibration scheme of spike CRMs from JRC-Geel G.2 and external CRMs (e.g. KRI RM, NBL CRMs) or proficiency test items (e.g. EQRAIN, IAEA-SAL) carried out in the laboratory in order to assure and guarantee the quality and conformity of the produced $\mathrm{U}$ and $\mathrm{Pu}$ certified reference materials.

These IDMS QC samples are now used to establish control charts to monitor regularly the IDMS results and identify possible errors, biases and/or outliers. They show, for instance, that the uncertainties on the U IDMS measurement results were likely underestimated, as also apparent from JRC-Geel G.2's performance results in external PTs (e.g. in EQRAIN circuits from CEA/CETAMA). Using the results from the control chart of the U QC sample, an additional uncertainty component for the U ID-TIMS measurements was determined, leading to a better estimate of the combined standard measurement uncertainty on the $\mathrm{U}$ amount content.

The JRC-Geel G.2 is therefore currently using the RSD of the analysed U QC samples as an additional uncertainty to make the uncertainties associated with the U IDMS measurement results more fit for purpose. Consequently, the typical current uncertainties for $\mathrm{Pu}$ and $\mathrm{U}$ amount contents determined by ID-TIMS at JRC-Geel G.2 are of around 0.12 and $0.08 \%(k=2)$, respectively, and remain fit for purpose. However, other ways of estimating the uncertainty that might further optimize the IDMS method are currently being investigated, such as the Monte Carlo Method (MCM) for the validation of the GUM Uncertainty Framework (GUF).

Acknowledgements The authors are grateful to the JRC-Geel G.2 colleagues, Stephan Richter and Ulf Jacobsson, for their support in the mass spectrometry measurements and to Frances Kehoe for her support in the different chemical purifications. The authors would like to thank Renáta Buják for her contribution to the analysis and use of the QC samples in the context of the certification of the IRMM-1027 LSD spikes.

Open Access This article is licensed under a Creative Commons Attribution 4.0 International License, which permits use, sharing, adaptation, distribution and reproduction in any medium or format, as long as you give appropriate credit to the original author(s) and the source, provide a link to the Creative Commons licence, and indicate if changes were made. The images or other third party material in this article are included in the article's Creative Commons licence, unless indicated otherwise in a credit line to the material. If material is not included in the article's Creative Commons licence and your intended use is not permitted by statutory regulation or exceeds the permitted use, you will need to obtain permission directly from the copyright holder. To view a copy of this licence, visit http://creativecommons.org/licenses/by/4.0/.

\section{References}

1. ISO/IEC 17025:2005 (2005) General requirements for the competence of testing and calibration laboratories. International organisation for standardisation, Geneva, Switzerland

2. ISO/IEC 17034:2016 (2016) General requirements for the competence of reference material producers. International organisation for standardisation, Geneva, Switzerland

3. ISO Guide 35:2017 (2017) Reference materials-General and statistical principles for certification. International organisation for standardisation, Geneva, Switzerland

4. EURACHEM/CITAC Guide (2016) Guide to quality in analytical chemistry 3rd edn

5. EURACHEM/CITAC Guide (2012) Quantifying Uncertainty in Analytical Measurement 3rd edn

6. ISO/IEC Guide 98-3:2008 (2008) Evaluation of measurement uncertainty-Guide to the expression of uncertainty in measurement (GUM). International organisation for standardisation. Geneva, Switzerland

7. JCGM 200:2012 (2012) International Vocabulary of MetrologyBasic and general concepts and associated terms (VIM) 3rd edn

8. GUM Workbench Pro Version 2.4.1.458 1996-2016 (2009) Metrodata $\mathrm{GmbH}$, Braunschweig, Germany

9. Wellum R, Berglund M (2002) The application of the guide to uncertainty in measurements in safeguards. ESARDA Bull $31: 11-14$

10. ISO Guide 33:2015 (2015) Reference materials-good practice in using reference materials. International organisation for standardisation. Geneva, Switzerland

11. ISO Guide 80:2014 (2014) Guidance for the in-house preparation of quality control materials (QCMs). International organisation for standardisation. Geneva, Switzerland

12. ISO 7870-1:2014 (2014) Control charts-Part 1: general guidelines. International organisation for standardisation. Geneva, Switzerland

13. Vogl J, Pritzkow W (2010) Isotope dilution mass spectrometry-a primary method of measurement and its role for RM certification. J Metrol Soc India 25(3):135-164 
14. Milton MJT, Quinn TJ (2001) Primary methods of the measurement of amount of substance. Metrologia 38:289-296

15. De Bievre P (1993) Isotope dilution mass spectrometry as a primary method of analysis. Anal Proc 30:328-333

16. Berych W, Golly W, Spannegel G, De Bievre P, Wolteres WH, Lycke W (1986) The assay of uranium and plutonium in reprocessing input solutions by isotope dilution mass spectrometry: results of the isotope dilution analysis measurement evaluation programs. Nucl Technol 75:73-81

17. New Brunswick Laboratory Program Office, https://science.osti. gov/nbl/Certified-Reference-Materials/Prices-and-Certificates

18. Byerly BL, Stanley F, Spencer K, Colletti L, Garduno K, Kuhn K, Lujan E, Martinez A, Portefield D, Rim J, Schappert M, Thomas M, Townsend L, Xu N, Tandon L (2016) Forensic investigation of plutonium metal: a case study of CRM 126. J Radioanal Nucl Chem 310:623-632

19. Mathew KJ, Essex RM, Hasozbek A, Orlowicz G, Soriano M (2014) Uranium isotope-amount ratios in certified reference material 116-A-Uranium (enriched) metal assay and isotopic standard. Int J Mass Spect 369:48-58

20. Essex RM, Orlowicz G, Hui N, Gradle C, Voeks A, Hasozbek A, Hawk TC, Mathew KJ (2015) Certified Reference Material 116-A: a new high-enriched uranium metal standard. J Nucl Mater Manage 43(3):4-16

21. Crozet M, Roudil D, Rigaux C, Bertorello C, Picart S, Maillard C (2019) EQRAIN: uranium and plutonium interlaboratory exercises from 1997 to 2016 - comparison to ITVs-2010. J Radioanal Nucl Chem. https://doi.org/10.1007/s10967-018-6399-7

22. Guidelines on the calibration of non/automatic weighing instruments (03/2011) EURAMET cg-18, Version 3.0

23. OIML R111-1 (2004) Weights of classes E1, E2, F1, F2, M1, M1-2, M2, M2-3 and M3, Part 1: metrological and technical requirements, International organisation of legal metrology, Paris, France

24. Jakopic R, Bauwens J, Buják R, Hennessy C, Kehoe F, Jacobsson U, Richter S, Aregbe Y (2018) Preparation and certification of large-sized dried (LSD) spikes-IRMM-1027s. EUR 29274 EN. https://crm.jrc.ec.europa.eu/p/q/IRMM-1027s/IRMM-1027s -U-Pu-ORGANIC/IRMM-1027s. Accessed 08 Sept 2020

25. De Bievre $\mathrm{P}$ (1965) Isotope dilution mass spectrometry as a primary method of analysis. Nucl Instrum Methods 32:224-228

26. Jakopic R, Verbruggen A, Eykens R, Kehoe F, Kuhn H, Kushigeta Y, Jacobsson U, Bauwens J, Richter S, Wellum R, Aregbe $\mathrm{Y}$ (2010) An inter-calibration campaign using various selected $\mathrm{Pu}$ spike isotopic reference materials. J Radioanal Nucl Chem 286:449-454

27. Aggarwal SK, Kumar S, Saxena MK, Shah PM, Jain HC (1995) Investigations for isobaric interference of $238 \mathrm{Pu}$ at $238 \mathrm{U}$ during thermal ionization mass spectrometry of uranium and plutonium from the same filament loading. Int J Mass Spectrom Ion Process 151:127-135

28. Richter S, Goldberg SA (2003) Improved techniques for high accuracy isotope ratio measurements of nuclear materials using thermal ionisation mass spectrometry. Int J Mass Spectr 229:181-197
29. Callis EL, Abernathey RM (1991) High precision isotopic analysis of uranium and plutonium by total sample volatilization and signal integration. Int J Mass Spectr Ion Process. https://doi. org/10.1016/0168-1176(91)80081-W

30. C1672-17: Standard test method for determination of uranium and plutonium isotopic composition or concentration by total evaporation method using a thermal ionisation mass spectrometer, ASTM International

31. Boulyga S, Kappel SK, Richter S, Sangely L (2015) Mass spectrometric analysis for nuclear safeguards. J Anal At Spectr 30:1469-1489

32. Laboratoire national henry becquerel http://www.nucleide.org/ DDEP_WG/DDEPdata.htm. Accessed 08 Sept 2020

33. Wellum R, Verbruggen A, Kessel R (2009) A new evaluation of the half-life of 241Pu. J Anal At Spectrom 24:801-807

34. Wang M, Audi G, Kondev FG, Huang WJ, Naimi S, Xu X (2017) The AME 2016 atomic mass evaluation (II). Tables, Graphs and References. Chinese Physics C. https://doi.org/10.1088/16741137/41/3/030003

35. Jakopič R, Bauwens J, Buják R, Hennessy C, Kehoe F, Jacobsson U, Toth K, Richter S, Aregbe Y (2019) Preparation and certification of large-sized dried (LSD) spikes-IRMM-1027t. EUR 29742. https://crm.jrc.ec.europa.eu/p/q/irmm-1027t+/IRMM-1027t/ IRMM-1027t. Accessed 08 Sept 2020

36. Buják R. Toth K, Bauwens J, Hennessy C, Kehoe F, Jacobsson U, Richter S, Aregbe Y (2020) Preparation and certification of large-sized dried (LSD) spikes-IRMM-1027u. EUR 30137 EN

37. Jakopic R, Aregbe Y, Richter S, Zuleger E, Mialle S, Balsley SD, Repinc U, Hiess J (2017) Verification measurements of the IRMM-1027 and the IAEA large-sized dried (LSD) spikes. J Radioanal Nucl Chem. https://doi.org/10.1007/s10967-016-5123-8

38. Richter S, Kuhn H, Aregbe Y, Hedberg M, Horta-Domenech J, Mayer K, Zuleger E, Burger S, Boulyga S, Kopft A, Poths J, Mathew K (2010) Improvements in routine uranium isotope ratio measurements using the modified total evaporation method for multi-collector thermal ionization mass spectrometry. J Anal At Spectr 26:550-564

39. Kessel R, Berglund M, Wellum R (2008) Application of consistency checking to evaluation of uncertainty in multiple replicate measurements. Accred Qual Assur 13:293-298

40. Vogl J (2013) Advances in Isotope Ratio Mass Spectrometry and Required Isotope Reference Materials. The Mass Spectr Soc Japan. https://doi.org/10.5702/massspectrometry.S0020

41. ISO/IEC Guide 98-3/Suppl.1 (2008) Evaluation of measurement uncertainty-(GUM) Suppl.1 Propagation of distributions using a Monte Carlo method. International organisation for standardisation, Geneva, Switzerland

Publisher's Note Springer Nature remains neutral with regard to jurisdictional claims in published maps and institutional affiliations. 